\title{
CD133, Stem Cells, and Cancer Stem Cells: Myth or Reality?
}

\author{
Xiazhen Yu • Yingjie Lin • Xie Yan • Qiang Tian • \\ Linheng Li $\cdot$ Edward H. Lin
}

Published online: 17 September 2011

(C) Springer Science+Business Media, LLC 2011

\begin{abstract}
CD133, a member of the prominin family, is found in a variety of tissues with at least three variants. The function of CD133 is not well understood, but its expression is subject to changes in the microenvironment cues including bioenergetic stress. Knockout of CD133 does not affect renewal, but mammary gland branching. A point mutation of CD133 (R733C) leads to retinal disorder. CD133 is found in embryonic stem cells, normal tissue
\end{abstract}

X. Yu $\cdot$ E. H. Lin

Seattle Cancer Care Alliance, University of Washington, Institute for Stem Cell and Regenerative Medicine,

Seattle, WA 98109, USA

X. Yu $\cdot$ L. Li

Stowers Institute for Medical Research,

Kansas City, MO 64110, USA

\section{$\mathrm{X} . \mathrm{Yu}$}

Department of Hepatobiliary Surgery, The First Affiliated

Hospital, School of Medicine, Zhejiang University,

Key Laboratory of Multi-Organ Transplantation of Ministry

of Public Health,

Hangzhou, China

Y. Lin $\cdot$ X. Yan

Beijing Cancer Hospital, Peking University School of Medicine, and Peking University Stem Cell Research Center (SCRC), 914\# Peking University, Center Building 38\# XueYuan Road in HaiDian Block,

Beijing 10001, China

\section{Q. Tian}

Institute of System Biology,

1441 North 34th Street,

Seattle, WA 98103-8904, USA

E. H. Lin $(\bowtie)$

825 Eastlake Avenue SE G4818,

Seattle, WA 98004, USA

e-mail: elin@seattlecca.org stem cells, stem cell niches, and circulating endothelial progenitors as well as cancer stem cells. Maintenance of stemness in cancer may be attributable to asymmetric cell division in association with a set of embryonic expression signatures in CD133+ tumor cells. CD133 could enrich cancer stem cells, which are associated with chemo- and radiation resistance phenotype. High CD133 is associated with poor survival in a variety of solid tumors, including lung, colon, prostate, etc. Monitoring CD133+ cells in peripheral blood, and targeting CD133 in cancer, may further predict and improve the clinical outcomes.

Keywords CD133 · Cancer stem cells · Endothelial progenitors $\cdot$ Colorectal cancer

\section{Introduction}

CD133 (or AC133), a member of prominin family, was first discovered from hematopoietic stem cells initially discovered in 1997 by Yin and colleagues [1••, 2•]. At the same time, Asahara and others reported that bone marrowderived circulating endothelial progenitors (CEP) participate in postnatal angiogenesis including tumor, inflammation, and tissue regeneration $[3,4 \bullet \cdot]$. Interestingly, CEP express CD133, which has been recently used to enrich and mark normal tissue stem cells as well as cancer stem cells from a variety of solid tumors [5••, 6-12]. CD133 can enrich cancel stem cells (CSC) up to approximately 200fold from the human tumor tissue, and these CSC exhibit limitless self-renewal capacity, sustain long-term culture, and form tumor xenograft in immunodeficient mice that fully recapitulate the pathological features of the human tumor [5••, 6-12]. A single CD133-positive colon cancer cell is capable of differentiating into neuroendocrine, 
goblet, and glandular lineages meeting the current definition of cancer stem cells [13]. Likewise, CD133+ glioblastoma stem cells could give rise to tumor endothelium, likely through a transit amplifying CD133+ cell fraction [14•].

While some studies disputed the specificity of the CD133 as a CSC marker [10,15], others had used CD24 $4^{\text {low }}$, CD44 $4^{\text {high }}$, or aldehyde dehydrogenase $+/-$ CD133 to enrich for CSC from tumors of the breast, pancreas, and colon, etc. [16-19]. CD133 + CSC admittedly overlap with CD24 $4^{\text {low }}$ and $\mathrm{CD} 44^{\text {high }} \mathrm{CSC}$ fractions. Despite best enrichment methods, no less than 100 putative CSC are still required to form tumor xenograft in immunodeficient mice [20]. Previous CSC models favor the hierarchy model; however, most stem cell experts are increasingly receptive to a parallel hierarchy and stochastic CSC model to highlight the tumor heterogeneity and importance of microenvironment cues on CSC phenotype [21-23]. Regardless of the tumor model, clinical significance of putative CSC can only be established by studies that will examine the roles of CSC in cancer initiation, detection, monitoring, prognosis, treatment resistance, and molecular-targeted therapy. Due to space constraints, this review will focus only on some of the recent developments in CD133 and its relationship to CSC biology, and have readers refer to other reviews on CD44, ALDH, and CD24, etc. [24-27].

\section{Expression and Functions of CD133 in Cancer}

CD133 is a cholesterol interacting penta-span transmembrane glycoprotein $(120 \mathrm{kd})$ with two reported 3 isoforms CD133-1 [1••], CD133-2 [28], and CD133-3 [29]. CD133-1 mRNA was more prominent in fetal brain and adult skeletal muscle but was not detected in fetal liver and kidney, adult pancreas, kidney, and placenta. CD133-2, not CD133-1, is a cell surface antigen recognized by anti-CD133 monoclonal antibodies that are used for isolation of hematopoietic stem cells and is found in multiple stem cell niches marked by co-expression with $\beta$-integrin in the basal layer of human neonatal epidermis. Loss of CD133-2 correlates with gain in a terminal differentiation. Recently, another splice variant, CD133-3, was found in epididymis and testes [29]. Prominin is associated with membrane protrusions and vesicles export highly conserved across many different species [30, 31]. Extracellular membrane traffic may enable neural stem and progenitor cells to avoid the asymmetric inheritance of the midbody observed for other cells and, by releasing a stem cell membrane microdomain, to potentially influence the balance of their proliferation versus differentiation. Pine et al. [32•] showed that template DNA cosegregation was enhanced by cell-cell contact. Its frequency was densitydependent and modulated by environmental changes, including serum deprivation and hypoxia. Strikingly, during cell division, CD133 cosegregated with the template DNA, whereas the differentiation markers prosurfactant protein- $\mathrm{C}$ and pan-cytokeratins were passed to the opposing daughter cell, demonstrating that segregation of template DNA correlates with lung cancer cell fate [32].

Knockout of CD133 mice did not interestingly affect the regenerative capacity of mammary gland except the branching capacity [33]. A frame shift mutation (R373C) in prominin 1 (PROM1) has been shown to result in retinitis pigmentosa, macular degeneration, and cone-rod dystrophy in human patients possibly due to endothelial dysfunction, leading to impaired adhesion capacity and higher levels of cellular damage. Additionally, patient with this frame shift mutation suffered renal infections, hematuria, and recurrent miscarriages possibly reflecting consequences of abnormal tubular modeling.

The lineage tracing models showed that CD133 are found in the transit-amplifying zone of the colonic crypt which is susceptible to malignant transformation [7]. Indeed, CD133 is found on the putative cancer stem cells from a variety of solid tumors including brain [6], prostate [34], pancreas [35], melanoma [36, 37], colorectum [5••, 38], liver and bile duct $[39,40]$, lung, and ovary, etc. [7, 10, 41]. A number of important regulators and pathways have been implicated in CSC biology and CD133 expression: mTOR, Wnt $/ \beta$-catenin [42], PI3K-AKT [8, 13], reactive oxygen species-HIF1a pathway [43], Oct4 [9], and CXCR4 [35, 37]. Similar to embryonic stem cells, CD133+ colon cancer cells or melanoma expression are mostly found in the $\mathrm{G} 1 / \mathrm{G} 0$ portion of the cell cycle [36]. CD133 expression is due to the lack of $\mathrm{CpG}$ island methylation [44, 45]. Certain microRNA molecules (eg, miR-200a and miR130b) serve as stemness promoters [46, 47], whereas miR-34 serves as a stemness inhibitor [48]. Sorting and profiling human CD133+ glioblastoma multiforme (GBM) established a 214-gene signature which resembles that of human ES cells, and strongly correlates with histologic grade of GBM as well as breast and bladder cancer and portends poor survival [49••]. Finally, genomic instability plays an important role in the transformation of stem cells [50]. Function still not well understood, CD133 is broadly found among normal tissue stem cells as well as putative CSC population and serves as a marker of asymmetric division, lineage plasticity, tumor cell dormancy, and inherent embryonic gene expression. CD133 expression is under epigenetic regulation subject to microenvironment cues including chemotherapy and radiation (Fig. 1).

\section{Prognostic Values of CD133 Expression in Cancer and in Peripheral Blood}

To identify the link between CD133 and prognosis, most researchers had studied CD133 expression in correlation with 
Fig. 1 A view of CD133

expression as it relates to variety of normal tissue and cancer stem cells. CD133 expression is due to the lack of $\mathrm{CpG}$ island methylation and is regulated by several important pathways, including miR-200a, which serves as stemness promoter through the canonical $\mathrm{Wnt} / \beta$-catenin pathway. There are three reported isoforms, CD133-1, CD133-2, and CD133-3, which are detected in different tissue stem cells, niche, and normal tissues

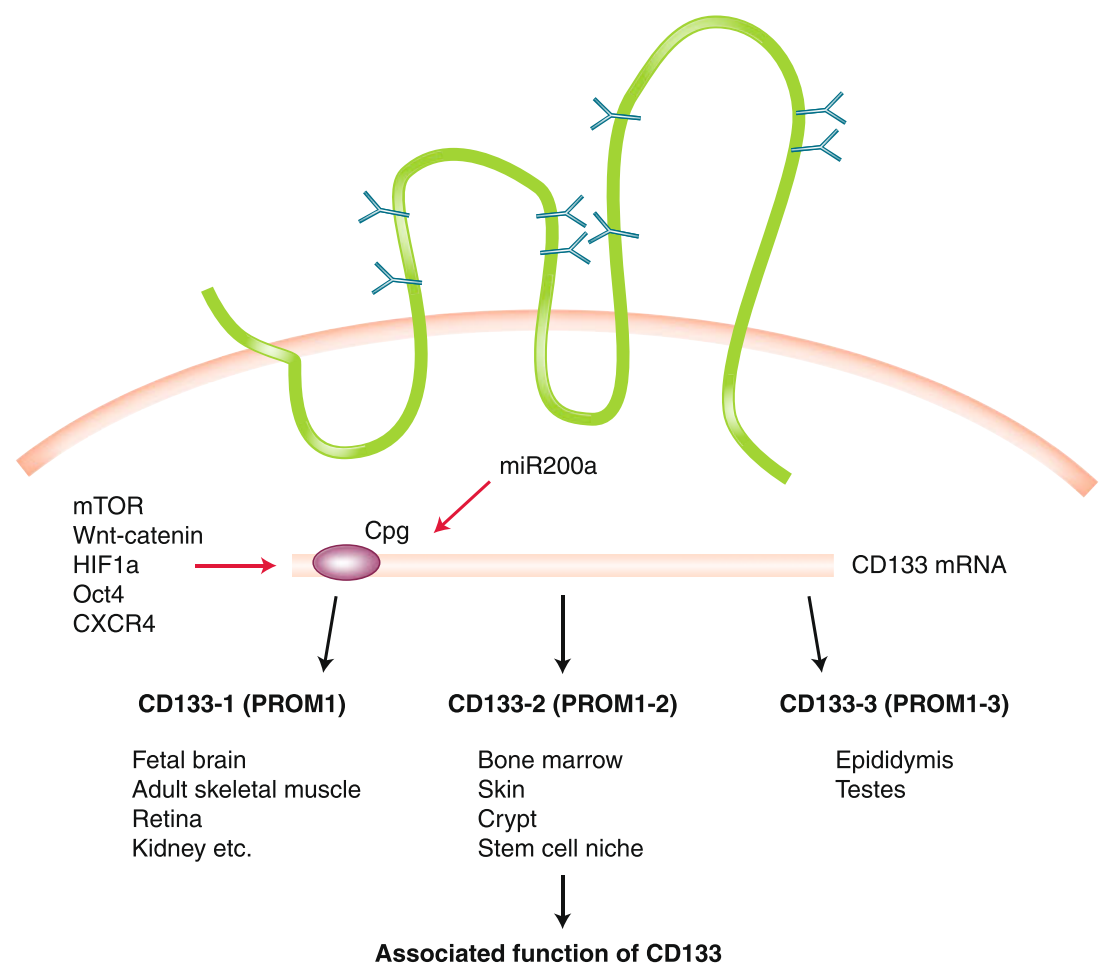

Membrane protrusions

Asymmetric cell division in cancer

Mammary gland branching

Bioenergetic stress

Macular degeneration and retinitis pigmentosa

Postnatal angiogenesis clinical and pathological parameters, especially survival, in a variety of tumors. High CD133 expression is associated with poor prognosis in cancers of the colorectum [51, 52, 53••, 54], brain [55, 56], liver [57], stomach [55], endometrium [58], ovary [41], and lung [59]. Most of these studies are small in sample size and are further limited by use of immunohistochemistry method, which results in high background noise with the commercial antibody. Some of the studies had utilized CD133 mRNA alone or in combination with other markers. Nevertheless, these studies are limited by relatively small sample size and retrospective study design and thus limit definitive conclusions. In support of the above findings, other work suggests that high CD133 expression in the tumor is due to resistance to cisplatin in lung cancer [11, 60], and drug resistance to $5 \mathrm{FU}$ in colorectal cancer [51]. Likewise, the resistance phenotype of colon cancer stem cells may be directly linked to cytokine IL-4, and modulating IL-4 could override the chemoresistance [61]. Similarly, high CD133 expression is also linked to radiation resistance and local relapse in rectal cancer and glioma [62-65]. Collectively, functions still poorly defined, CD133 is a putative CSC marker in a variety of solid tumors due to chemoresistance, and poor survival $[42,54]$.
CD133 also marks the circulating bone marrow-derived endothelial progenitor cells (CEP), which directly participate in tumor angiogenesis and form pre-metastatic niche [66, 67]. A number of assays had been developed to quantify CEP via flow cytometry, colony assay, and qRTPCR [68••]. When interpreting these results, one needs to consider the fact that elevated CD133 mRNA or CD133+ cells may also reflect circulating CD133+ CSC as well. Furthermore, a recent study showed that CD133+ glioblastoma cells were even capable of direct endothelial differentiation through $\mathrm{CD} 133+$ transit-amplifying progenitor [14•]. One study measured VEGFR2, CD133, CD34, and VE-cadherin mRNA in the peripheral blood samples and in lung cancer tissues. With confocal microscopy, putative CD133+ "EPCs" are found in 9 of 22 non-small cell lung cancer (NSCLC) tissues. Also, circulating EPC levels before therapeutic intervention were increased in NSCLC patients $(P<0.002$, vs healthy controls), and high pretreatment circulating EPC numbers correlated with poor overall survival $(P<0.001)$ [69]. Hermann and colleagues [35] identified the subset of CD133 + CXCR4+ cancer stem cells relates to the tumor metastasis in the pancreatic cancer model. We first showed that elevated CD133 mRNA levels 
Table 1 Prognosis of cancer with CD133 expression

\begin{tabular}{|c|c|c|c|c|c|}
\hline \multirow[t]{2}{*}{ Tumor type } & \multicolumn{2}{|c|}{ CD133 protein high expression } & \multicolumn{2}{|c|}{ CD133 mRNA high level } & \multirow[t]{2}{*}{ Reference } \\
\hline & Short survival & Relapse & Short survival & Relapse & \\
\hline Colorectal cancer & Yes & Yes & Yes & Yes & {$[42,51,52,53 \bullet \bullet, 54,68 \bullet \bullet, 71 \bullet \bullet, 72,73$} \\
\hline Ovarian & Yes & Yes & NA & NA & {$[41]$} \\
\hline Stomach & Yes & Yes & NA & NA & {$[55]$} \\
\hline Liver & Yes & Indeterminate & NA & NA & {$[57]$} \\
\hline Lung & Yes & Yes & NA & NA & {$[59]$} \\
\hline Brain & Yes & Yes & Yes & Yes & {$[55,56,62]$} \\
\hline
\end{tabular}

in peripheral blood predict colon cancer recurrence independent of tumor stage and serum CEA [68••]. Mehra et al. [70] also showed that elevated CD133 mRNA levels in peripheral blood were associated with bone metastasis and poor overall survival in a variety of solid tumors including colorectal cancer. Iinuma showed that peripheral blood CD133 mRNA was the most prognostic when combined with CK and CEA via RT-PCR in 735 stage II and III colorectal cancer patients. Interestingly, CD133 mRNA alone was reportedly not prognostic by Iinuma in stage II and III colorectal cancer, but was prognostic in two other studies that included stage IV patients [71••, 72, 73]. Earlier-stage diseases, small sample size, possibly technical difference, and timing of CD133 mRNA acquisition (preoperative vs postoperative) may explain the differences why CD133 mRNA was not prognostic in the current study. Our study included stage IV colorectal cancer patients who may shed more CD133+ circulating tumor cells [74]. Quantification of CD133+ cells using with flow cytometry or RT-PCR alone or in conjunction with other biomarkers may be useful to monitor treatment response to antiangiogenic agents including sorafenib plus erlotinib [75], and bevacizumab [76], and chemotherapy plus antiangiogenic agents [77].

Given its association with drug and radiation resistance and relationship to tumor angiogenesis, CD133 is considered to be a valid therapeutic target despite the lack of understanding on its function. A number of strategies have been tested: 1) A CD133 antibody conjugated to a potent cytotoxic drug, monomethyl auristatin F (MMAF), effectively inhibited the growth of Hep3B hepatocellular and KATO III gastric cancer cells in vitro and in vivo [78]. 2) Immunotherapy including adoptive immunotherapy targeting testicular antigen was also proposed [79]. CD133 is considered to be a target for melanoma immunotherapy [80]. 3) Using high-throughput CSC assays that undergo epithelial mesenchymal transition, Gupta et al. [81] had already yielded active small molecules of salinomycin that target breast CSC. Large pharmaceutical companies had put in greater resources of coming up with designer small molecules targeting its relevant pathways including sonic hedgehog, stat pathways, wnt pathway, etc. Some of these agents had entered into clinical trials (eg, anti-DLL4, MT110, IPI925, DI-Leu16-IL2, AZD7762) [82]. 4) Given that CSC is a functional definition and likely exists in a dynamic state and adapts to a functionally defining microenvironment including hypoxia etc., we proposed activation-depletion strategies targeting colon CSC in the clinic, which resulted in long-term survival outcomes in colorectal cancer [83].

\section{Conclusions}

The link between CD133 and normal and cancer stem cells is now firmly established. While not specific and function still is not clearly defined, CD133 is an important stemness biomarker in normal tissue stem cells as well as cancer stem cells. First used in colorectal cancer, CD133 can enrich the putative CSC from a variety of solid tumors and is associated with a set of embryonic gene signatures shared across many tumor types. High CD133 expression is associated with treatment resistance, relapse, and decreased survival in a variety of solid tumors, including colorectal cancer. More importantly, the prognostic value of circulating CD133 mRNA levels in advanced and locally advanced colorectal cancer is beginning to emerge. Given that CD133+ CEP and CSC may even overlap functionally through stem cell plasticity and inherent embryonic machinery, we will need to integrate strategies that will target the tumor bulk, CSC fraction, as well as the tumor microenvironment. Targeting and monitoring CD133 may lead to significant advances in outcome prediction and cancer therapy Table 1 .

Acknowledgment Xiazhen Yu and Yingjie Lin contributed equally to this review. 
Disclosure No potential conflicts of interest relevant to this article were reported.

\section{References}

Papers of particular interest, published recently, have been highlighted as:

- Of importance

•- Of major importance

1. •• Yin AH, Miraglia S, Zanjani ED, et al.: AC133, a novel marker for human hematopoietic stem and progenitor cells. Blood 1997;90:5002-12. This is the first paper that links AC133, later now named as CD133, to stem cells.

2. - Miraglia S, Godfrey W, Yin AH, et al.: A novel five-transmembrane hematopoietic stem cell antigen: isolation, characterization, and molecular cloning. Blood 1997;90:5013-21. This is the first paper to clone the CD133.

3. Asahara T, Murohara T, Sullivan A, et al. Isolation of putative progenitor endothelial cells for angiogenesis. Science. 1997;275:9647.

4. •- Shaked Y, Ciarrocchi A, Franco M, et al.: Therapy-induced acute recruitment of circulating endothelial progenitor cells to tumors. Science 2006;313:1785-7. This is the first paper to highlight the importance of endothelial progenitor cells.

5. •- Ricci-Vitiani L, Lombardi DG, Pilozzi E, et al.: Identification and expansion of human colon-cancer-initiating cells. Nature 2007;445:111-5. This is the first paper to isolate colon cancer stem cells.

6. Singh SK, Hawkins C, Clarke ID, et al. Identification of human brain tumour initiating cells. Nature. 2004;432:396-401.

7. Zhu L, Gibson P, Currle DS, et al. Prominin 1 marks intestinal stem cells that are susceptible to neoplastic transformation. Nature. 2009;457:603-7.

8. Ma S, Lee TK, Zheng BJ, et al. CD133+ HCC cancer stem cells confer chemoresistance by preferential expression of the Akt/PKB survival pathway. Oncogene. 2008;27:1749-58.

9. Chen YC, Hsu HS, Chen YW, et al. Oct-4 expression maintained cancer stem-like properties in lung cancer-derived CD133-positive cells. PLoS One. 2008;3:e2637.

10. Stewart JM, Shaw PA, Gedye C, et al. Phenotypic heterogeneity and instability of human ovarian tumor-initiating cells. Proc Natl Acad Sci U S A. 2011;108:6468-73.

11. Bertolini G, Roz L, Perego P, et al. Highly tumorigenic lung cancer $\mathrm{CD} 133+$ cells display stem-like features and are spared by cisplatin treatment. Proc Natl Acad Sci U S A. 2009;106:16281-6.

12. Leong KG, Wang BE, Johnson L, Gao WQ. Generation of a prostate from a single adult stem cell. Nature. 2008;456:804-8.

13. Vermeulen L, Todaro M, de Sousa Mello F, et al. Single-cell cloning of colon cancer stem cells reveals a multi-lineage differentiation capacity. Proc Natl Acad Sci U S A. 2008;105:13427-32.

14. • Wang R, Chadalavada K, Wilshire J, et al.: Glioblastoma stemlike cells give rise to tumour endothelium. Nature 2010;468:82933. This paper links the stem cells to tumor angiogenesis directly via CD133-expressing cells.

15. Shmelkov SV, Butler JM, Hooper AT, et al. CD133 expression is not restricted to stem cells, and both CD133+ and CD133metastatic colon cancer cells initiate tumors. J Clin Invest. 2008;118:2111-20.

16. Collins AT, Berry PA, Hyde C, et al. Prospective identification of tumorigenic prostate cancer stem cells. Cancer Res. 2005;65:1094651 .
17. Li C, Heidt DG, Dalerba $\mathrm{P}$, et al. Identification of pancreatic cancer stem cells. Cancer Res. 2007;67:1030-7.

18. Dalerba P, Dylla SJ, Park IK, et al. Phenotypic characterization of human colorectal cancer stem cells. Proc Natl Acad Sci U S A. 2007;104:10158-63.

19. Huang EH, Hynes MJ, Zhang T, et al. Aldehyde dehydrogenase 1 is a marker for normal and malignant human colonic stem cells (SC) and tracks SC overpopulation during colon tumorigenesis. Cancer Res. 2009;69:3382-9.

20. Yin $\mathrm{C}$, Lin $\mathrm{Y}$, Zhang $\mathrm{X}$, et al. Differentiation therapy of hepatocellular carcinoma in mice with recombinant adenovirus carrying hepatocyte nuclear factor-4alpha gene. Hepatology. 2008;48:1528-39.

21. Reya T, Morrison SJ, Clarke MF, Weissman IL. Stem cells, cancer, and cancer stem cells. Nature. 2001;414:105-11.

22. Roesch A, Fukunaga-Kalabis M, Schmidt EC, et al. A temporarily distinct subpopulation of slow-cycling melanoma cells is required for continuous tumor growth. Cell. 2010;141:583-94.

23. Pece S, Tosoni D, Confalonieri S, et al. Biological and molecular heterogeneity of breast cancers correlates with their cancer stem cell content. Cell. 2010;140:62-73.

24. Cho RW, Clarke MF. Recent advances in cancer stem cells. Curr Opin Genet Dev. 2008;18:48-53.

25. Zoller M. CD44: can a cancer-initiating cell profit from an abundantly expressed molecule? Nat Rev Cancer. 2011;11:254 67.

26. Todaro M, Francipane MG, Medema JP, Stassi G. Colon cancer stem cells: promise of targeted therapy. Gastroenterology. 2010;138:2151-62.

27. Marhaba R, Klingbeil P, Nuebel T, et al. CD44 and EpCAM: cancer-initiating cell markers. Curr Mol Med. 2008;8:784804.

28. Fargeas CA, Florek M, Huttner WB, Corbeil D. Characterization of prominin-2, a new member of the prominin family of pentaspan membrane glycoproteins. J Biol Chem. 2003;278:8586-96.

29. Fargeas CA, Joester A, Missol-Kolka E, et al. Identification of novel Prominin-1/CD133 splice variants with alternative C-termini and their expression in epididymis and testis. J Cell Sci. 2004;117:430111.

30. Corbeil D, Marzesco AM, Wilsch-Brauninger M, Huttner WB. The intriguing links between prominin-1 (CD133), cholesterolbased membrane microdomains, remodeling of apical plasma membrane protrusions, extracellular membrane particles, and (neuro)epithelial cell differentiation. FEBS Lett. 2010;584:165964.

31. Corbeil D, Roper K, Hannah MJ, et al. Selective localization of the polytopic membrane protein prominin in microvilli of epithelial cells - a combination of apical sorting and retention in plasma membrane protrusions. J Cell Sci. 1999;112(Pt 7):102333.

32. - Pine SR, Ryan BM, Varticovski L, et al.: Microenvironmental modulation of asymmetric cell division in human lung cancer cells. Proc Natl Acad Sci U S A 2010;107:2195-200. This is the first paper to link CD133 to asymmetric division in lung cancer cells.

33. Anderson LH, Boulanger CA, Smith GH, et al.: Stem cell marker prominin-1 regulates branching morphogenesis, but not regenerative capacity, in the mammary gland. Dev Dyn 2011.

34. Maitland NJ, Collins AT. Prostate cancer stem cells: a new target for therapy. J Clin Oncol. 2008;26:2862-70.

35. Hermann PC, Huber SL, Herrler T, et al. Distinct populations of cancer stem cells determine tumor growth and metastatic activity in human pancreatic cancer. Cell Stem Cell. 2007;1:313-23.

36. Jaksch M, Munera J, Bajpai R, et al. Cell cycle-dependent variation of a CD133 epitope in human embryonic stem cell, colon cancer, and melanoma cell lines. Cancer Res. 2008;68:7882-6. 
37. Kim M, Koh YJ, Kim KE, et al. CXCR4 signaling regulates metastasis of chemoresistant melanoma cells by a lymphatic metastatic niche. Cancer Res. 2010;70:10411-21.

38. O'Brien CA, Pollett A, Gallinger S, Dick JE. A human colon cancer cell capable of initiating tumour growth in immunodeficient mice. Nature. 2007;445:106-10.

39. Shimada M, Sugimoto K, Iwahashi S, et al. CD133 expression is a potential prognostic indicator in intrahepatic cholangiocarcinoma. J Gastroenterol. 2010;45:896-902.

40. Ma S, Chan KW, Lee TK, et al. Aldehyde dehydrogenase discriminates the CD133 liver cancer stem cell populations. Mol Cancer Res. 2008;6:1146-53.

41. Silva IA, Bai S, McLean K, et al.: Aldehyde dehydrogenase and CD133 define angiogenic ovarian cancer stem cells that portend poor patient survival. Cancer Res 2011.

42. Horst D, Kriegl L, Engel J, et al. CD133 and nuclear beta-catenin: the marker combination to detect high risk cases of low stage colorectal cancer. Eur J Cancer. 2009;45:2034-40.

43. Matsumoto K, Arao T, Tanaka K, et al. mTOR signal and hypoxia-inducible factor-1 alpha regulate CD133 expression in cancer cells. Cancer Res. 2009;69:7160-4.

44. Yi JM, Tsai HC, Glockner SC, et al. Abnormal DNA methylation of CD133 in colorectal and glioblastoma tumors. Cancer Res. 2008;68:8094-103.

45. Baba T, Convery PA, Matsumura N, et al. Epigenetic regulation of CD133 and tumorigenicity of CD133+ ovarian cancer cells. Oncogene. 2009;28:209-18.

46. Xia H, Cheung WK, Sze J, et al. miR-200a regulates epithelialmesenchymal to stem-like transition via ZEB2 and beta-catenin signaling. J Biol Chem. 2010;285:36995-7004.

47. Ma S, Tang KH, Chan YP, et al. miR-130b Promotes CD133(+) liver tumor-initiating cell growth and self-renewal via tumor protein 53-induced nuclear protein 1. Cell Stem Cell. 2010;7:694707.

48. Ji Q, Hao X, Zhang M, et al. MicroRNA miR-34 inhibits human pancreatic cancer tumor-initiating cells. PLoS One. 2009;4: e6816.

49. •- Yan X, Ma L, Yi D, et al.: A CD133-related gene expression signature identifies an aggressive glioblastoma subtype with excessive mutations. Proc Natl Acad Sci U S A 2011;108:1591-6. This is the first paper to describe a CD133-related gene expression signature in GBM, and these signatures are shared among other tumor types.

50. Liang Y, Zhong Z, Huang Y, et al. Stem-like cancer cells are inducible by increasing genomic instability in cancer cells. J Biol Chem. 2010;285:4931-40.

51. Li CY, Li BX, Liang Y, et al. Higher percentage of CD133+ cells is associated with poor prognosis in colon carcinoma patients with stage IIIB. J Transl Med. 2009;7:56.

52. Xi HQ, Zhao P: Clinicopathological significance and prognostic value of EphA3 and CD133 expression in colorectal carcinoma. $\mathrm{J}$ Clin Pathol 2011.

53. •- Artells R, Moreno I, Diaz T, et al.: Tumour CD133 mRNA expression and clinical outcome in surgically resected colorectal cancer patients. Eur J Cancer 2010;46:642-9. Prognostic value of CD133 mRNA in colorectal cancer is proposed.

54. Horst D, Kriegl L, Engel J, et al. CD133 expression is an independent prognostic marker for low survival in colorectal cancer. Br J Cancer. 2008;99:1285-9.

55. Ishigami $\mathrm{S}$, Ueno $\mathrm{S}$, Arigami $\mathrm{T}$, et al. Prognostic impact of CD133 expression in gastric carcinoma. Anticancer Res. 2010;30:24537.

56. Metellus P, Nanni-Metellus I, Delfino C, et al.: Prognostic Impact of CD133 mRNA Expression in 48 Glioblastoma Patients Treated with Concomitant Radiochemotherapy: A Prospective Patient Cohort at a Single Institution. Ann Surg Oncol 2011.
57. Sasaki A, Kamiyama T, Yokoo H, et al. Cytoplasmic expression of CD133 is an important risk factor for overall survival in hepatocellular carcinoma. Oncol Rep. 2010;24:537-46.

58. Nakamura M, Kyo S, Zhang B, et al. Prognostic impact of CD133 expression as a tumor-initiating cell marker in endometrial cancer. Hum Pathol. 2010;41:1516-29.

59. Woo T, Okudela K, Mitsui H, et al. Prognostic value of CD133 expression in stage I lung adenocarcinomas. Int J Clin Exp Pathol. 2010;4:32-42.

60. Levina V, Marrangoni AM, DeMarco R, et al. Drug-selected human lung cancer stem cells: cytokine network, tumorigenic and metastatic properties. PLoS One. 2008;3:e3077.

61. Todaro M, Alea MP, Di Stefano AB, et al. Colon cancer stem cells dictate tumor growth and resist cell death by production of interleukin-4. Cell Stem Cell. 2007;1:389-402.

62. Bao S, Wu Q, McLendon RE, et al. Glioma stem cells promote radioresistance by preferential activation of the DNA damage response. Nature. 2006;444:756-60.

63. Murat A, Migliavacca E, Gorlia T, et al. Stem cell-related "selfrenewal" signature and high epidermal growth factor receptor expression associated with resistance to concomitant chemoradiotherapy in glioblastoma. J Clin Oncol. 2008;26:3015-24.

64. Saigusa S, Tanaka K, Toiyama Y, et al. Correlation of CD133, OCT4, and SOX2 in rectal cancer and their association with distant recurrence after chemoradiotherapy. Ann Surg Oncol. 2009;16:3488-98.

65. Nagata T, Sakakura C, Komiyama S, et al. Expression of cancer stem cell markers CD133 and CD44 in locoregional recurrence of rectal cancer. Anticancer Res. 2011;31:495-500.

66. Borovski T, De Sousa EMF, Vermeulen L, Medema JP. Cancer stem cell niche: the place to be. Cancer Res. 2011;71:634-9.

67. Kaplan RN, Riba RD, Zacharoulis S, et al. VEGFR1-positive haematopoietic bone marrow progenitors initiate the premetastatic niche. Nature. 2005;438:820-7.

68. • Lin EH, Hassan M, Li Y, et al.: Elevated circulating endothelial progenitor marker CD133 messenger RNA levels predict colon cancer recurrence. Cancer 2007;110:534-42. This is the first paper to describe the prognostic value of CD133 mRNA in colorectal cancer.

69. Dome B, Timar J, Dobos J, et al. Identification and clinical significance of circulating endothelial progenitor cells in human non-small cell lung cancer. Cancer Res. 2006;66:7341-7.

70. Mehra N, Penning M, Maas J, et al. Progenitor marker CD133 mRNA is elevated in peripheral blood of cancer patients with bone metastases. Clin Cancer Res. 2006;12:4859-66.

71. •- Iinuma H, Watanabe T, Mimori K, et al.: Clinical significance of circulating tumor cells, including cancer stem-like cells, in peripheral blood for recurrence and prognosis in patients with Dukes' Stage B and C Colorectal Cancer. J Clin Oncol 2011. This is the first paper to describe the role of CD133 mRNA in stage B and $C$ colorectal cancer.

72. Iinuma $\mathrm{H}$, Okinaga $\mathrm{K}$, Egami $\mathrm{H}$, et al. Usefulness and clinical significance of quantitative real-time RT-PCR to detect isolated tumor cells in the peripheral blood and tumor drainage blood of patients with colorectal cancer. Int J Oncol. 2006;28:297-306.

73. Nakamura K, Iinuma H, Aoyagi Y, et al. Predictive value of cancer stem-like cells and cancer-associated genetic markers for peritoneal recurrence of colorectal cancer in patients after curative surgery. Oncology. 2010;78:309-15.

74. Tralhao JG, Hoti E, Serodio M, et al. Perioperative tumor cell dissemination in patients with primary or metastatic colorectal cancer. Eur J Surg Oncol. 2010;36:125-9.

75. Vroling L, Lind JS, de Haas RR, et al. CD133+ circulating haematopoietic progenitor cells predict for response to sorafenib plus erlotinib in non-small cell lung cancer patients. Br J Cancer. 2010;102:268-75. 
76. Willett CG, Boucher Y, di Tomaso E, et al. Direct evidence that the VEGF-specific antibody bevacizumab has antivascular effects in human rectal cancer. Nat Med. 2004;10:145-7.

77. Calleri A, Bono A, Bagnardi V, et al. Predictive potential of angiogenic growth factors and circulating endothelial cells in breast cancer patients receiving metronomic chemotherapy plus bevacizumab. Clin Cancer Res. 2009;15:7652-7.

78. Smith LM, Nesterova A, Ryan MC, et al. CD133/prominin-1 is a potential therapeutic target for antibody-drug conjugates in hepatocellular and gastric cancers. Br J Cancer. 2008;99:100-9.

79. Gedye C, Quirk J, Browning J, et al. Cancer/testis antigens can be immunological targets in clonogenic CD133+ melanoma cells. Cancer Immunol Immunother. 2009;58:1635-46.
80. Rappa G, Fodstad O, Lorico A. The stem cell-associated antigen CD133 (Prominin-1) is a molecular therapeutic target for metastatic melanoma. Stem Cells. 2008;26:3008-17.

81. Gupta PB, Onder TT, Jiang G, et al. Identification of selective inhibitors of cancer stem cells by high-throughput screening. Cell. 2009;138:645-59.

82. Zhou BB, Zhang H, Damelin M, et al. Tumour-initiating cells: challenges and opportunities for anticancer drug discovery. Nat Rev Drug Discov. 2009;8:806-23.

83. Lin $\mathrm{E}, \mathrm{He} \mathrm{X}$, Yan XW, et al.: Efficiently targeting cancer stem cells requires tactical activation from their dormant state and subsequent exhaustion. Proceedings of American Association of Cancer Research 2010;LB254. 